\title{
Avaliação Espaço-Temporal das Águas dos Afluentes do Reservatório da UHE Barra dos Coqueiros/Goiás
}

\author{
Hudson Moraes Rocha ${ }^{1}$, João Batista Pereira Cabral ${ }^{1}$, Celso Carvalho Braga ${ }^{2}$ \\ sauhudson@gmail.com; jbcabral2000@yahoo.com.br; ccarvalhobraga@gmail.com \\ Recebido: 11/03/13 - revisado: 07/05/13 - aceito: 31/10/13
}

\begin{abstract}
RESUMO
A construção de empreendimentos hidráulicos interfere profundamente nas propriedades físicas, químicas e biológicas da água. O presente trabalho teve por objetivo analisar espacial e temporalmente as características físicas e químicas das águas dos afluentes do reservatório da Usina Hidrelétrica (UHE) Barra dos Coqueiros, no estado de Goiás, a fim de identificar fatores que interferem na qualidade da água. As coletas das águas nos afluentes foram realizadas em intervalos de aproximadamente 30 dias no periodo de um ano. Os parâmetros avaliados foram: temperatura da água, potencial hidrogeniôni$c 0$, total de sólidos dissolvido, condutividade elétrica, salinidade, resistividade elétrica, e turbidez. Os resultados mostram que alguns dos afluentes apresentam inadequabilidade dos parâmetros físicos e químicos da água de acordo com a Resolução CONAMA № 357/2005.
\end{abstract}

Palavras-chave: Meio ambiente, Recurso hídrico, Bacia hidrográfica

\section{INTRODUÇÃO}

Os ecossistemas aquáticos se interrelacionam com as propriedades físico-geográficas (bacia hidrográfica, geologia, geomorfologia, uso e ocupação e rede drenagem), que conferem características próprias a cada ecossistema.

O monitoramento ambiental das águas em sistemas lóticos e lênticos é de grande importância, pois as medidas dos parâmetros físicos, químicos e biológicos permitem detectar tendências ou alterações na qualidade das águas.

A água, devido às suas propriedades de solvente e à sua capacidade de transportar partículas, incorpora a si diversas impurezas, as quais definem sua qualidade. Dessa forma, pode-se dizer que a qualidade da água é determinada em função do uso e da ocupação do solo na bacia hidrográfica.

A água é essencial para a garantia da qualidade de vida, para a produção agropecuária e industrial, para a prestação de serviços e para todas as atividades humanas. Nos diferentes ambientes, a água é o principal elo entre os componentes, sendo, por isso, identificadora da qualidade ambiental de um ecossistema, de uma região ou bacia hidrográfica (HERMES \& SILVA, 2004).

1 - Universidade Federal de Goiás

${ }^{2-}$ Instituto Federal de Goiás
O monitoramento dos parâmetros físicoquímicos tais como $\mathrm{pH}$, temperatura, condutividade elétrica, turbidez, entre outros parâmetros em águas doces, são necessários para determinar padrões de qualidade e, a partir das análises, são sugeridos ou não outros tipos de investigação para se descobrir o nível de degradação de uma bacia.

Diante desses pressupostos, este trabalho traz resultados das análises, de forma espaçotemporal, da qualidade da água dos afluentes do reservatório da Usina Hidrelétrica (UHE) Barra dos Coqueiros, para identificar os fatores que interferem na qualidade da água.

\section{MATERIAL E MÉTODOS}

\section{Caracterização da área de estudo}

A bacia hidrográfica da UHE Barra dos Coqueiros está localizada no baixo curso do rio Claro, ao Sudoeste do Estado de Goiás, entre os municípios de Caçu e Cachoeira Alta, delimitada entre as coordenadas UTM E=479338m, E=509087m e $\mathrm{N}=7923981 \mathrm{~m}, \mathrm{~N}=7956739 \mathrm{~m}$, mapeados pelas folhas SE-22-Y-B e SE-22-Z-A (IBGE, 1978) (Figura 1).

De acordo com o estudo apresentado por Rocha (2011), a área desmatada para o uso antrópico (Pastagem, cultura, centro urbano e áreas de plantio) na bacia da UHE Barra dos Coqueiros é de 
$77,2 \%$, enquanto a vegetação destinada à reserva legal e proteção dos cursos d'água (Mata e Cerrado) é de aproximadamente $18,3 \%$, e $4,5 \%$ de corpo d'água.

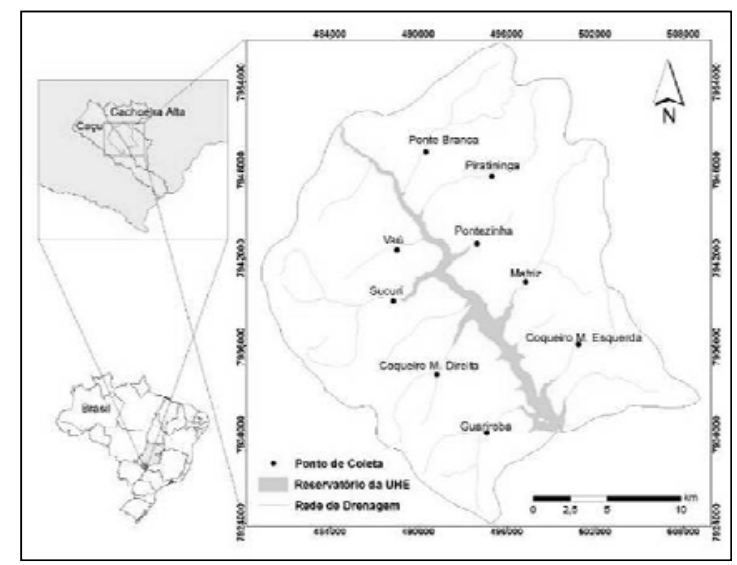

Figura 1- Localização dos pontos de amostragem nos afluentes da UHE Barra dos Coqueiros/Caçu-GO.

Para o monitoramento ambiental da água foram estabelecidos pontos de coleta nos principais afluentes da bacia hidrográfica da UHE Barra dos Coqueiros (Figura 1). As leituras das variáveis físicoquímicas foram feitas em campo, em horários fixos para que a flutuação da temperatura influenciasse o mínimo possível nos resultados. As visitas de campo seguiram o intervalo de aproximadamente 30 dias, fazendo uma coleta por ponto em cada mês, no período de setembro de 2010 a agosto de 2011. Os afluentes estudados da UHE Barra dos Coqueiros estão apresentados no Quadro 1.

Quadro 1 - Descrição dos afluentes da UHE Barra dos Coqueiros.

\begin{tabular}{|c|c|c|c|c|}
\hline \hline Ponto & Tributário & $\begin{array}{c}\text { Largura } \\
\text { média } \\
(\mathrm{m})\end{array}$ & $\begin{array}{c}\text { Profundidade } \\
\text { média }(\mathrm{m})\end{array}$ & $\begin{array}{c}\text { Vazão } \\
\text { média } \\
\left(\mathrm{m}^{3} / \mathrm{s}\right)\end{array}$ \\
\hline 1 & $\begin{array}{c}\text { Ponte } \\
\text { Branca }\end{array}$ & 6,0 & 0,41 & 0,82 \\
\hline 2 & Piratininga & 3,0 & 0,15 & 0,59 \\
\hline 3 & Pontezinha & 3,5 & 0,62 & 0,40 \\
\hline 4 & Matriz & 7,1 & 0,30 & 1,29 \\
\hline 5 & $\begin{array}{c}\text { C. } \text { Esquer- } \\
\text { do }\end{array}$ & 5,0 & 0,47 & 0,49 \\
\hline 6 & Guariroba & 1,5 & 0,38 & 0,22 \\
\hline 7 & C.Direito & 1,0 & 0,25 & 0,30 \\
\hline 8 & Sucuri & 3,6 & 0,70 & 0,99 \\
\hline 9 & Vau & 1,5 & 0,25 & 0,19 \\
\hline \hline
\end{tabular}

Os parâmetros físicos e químicos das águas avaliados foram: temperatura da água $\left({ }^{\circ} \mathrm{C}\right)$, potencial hidrogeniônico $(\mathrm{pH})$, total de sólidos dissolvido (TDS), condutividade elétrica (CE), salinidade $(\mathrm{NaCl})$, resistividade elétrica (RE), e turbidez (TURB). Para as leituras das amostras de água utilizou-se dos equipamentos multiparâmentro, marca Oakton, modelo PCD650, e do Turbidímetro Portátil, modelo HI 93703 (Hanna). Os procedimentos de análise de água seguiram a descrição do Standard Methods for the Examination of Water and Wastewater (APHA-1998).

\section{Análise de regressão linear}

Os resultados das análises das águas foram planificados e submetidos a tratamento estatístico computacional que permitiu a elaboração de tabelas e gráficos.

A análise de regressão linear foi aplicada para indicar o grau de associação entre as variáveis físicas e químicas da água, com dados nas escalas de "intervalos ou de razões", podendo a correlação variar de $+1 \mathrm{a}-1$.

Visando discutir as medidas de coeficiente de correlação linear foram estabelecidos intervalos de correlação (variando de +1 a -1 ) (Quadro 2), adaptado do trabalho de Santos (2007).

Quadro 2 - Intervalos do coeficiente de correlação linear.

\begin{tabular}{|l|l|}
\hline \hline Coeficiente de correlação & Correlação \\
\hline $\mathrm{r}=1$ & Perfeita positiva \\
\hline $0,7 \leq \mathrm{r}<1$ & Forte positiva \\
\hline $0,4 \leq \mathrm{r}<0,7$ & Moderada positiva \\
\hline $0,1 \leq \mathrm{r}<0,4$ & Fraca positiva \\
\hline $0<\mathrm{r}<0,1$ & Ínfima positiva \\
\hline 0 & Nula \\
\hline$-0,1<\mathrm{r}<0$ & Ínfima negativa \\
\hline$-0,4<\mathrm{r} \leq-0,1$ & Fraca negativa \\
\hline$-0,7<\mathrm{r} \leq-0,4$ & Moderada negativa \\
\hline$-1<\mathrm{r} \leq-0,7$ & Forte negativa \\
\hline $\mathrm{r}=-1$ & Perfeita negativa \\
\hline \hline
\end{tabular}

\section{RESULTADOS E DISCUSSÃO}

\section{Avaliação qualitativa dos dados de água}

A distribuição temporal dos valores da qualidade de água, com base nas datas de coleta de setembro de 2010 a agosto de 2011, demonstrou 
variações significativas de valores dos parâmetros físico-químicos de água entre os tributários.

No Gráfico 1 são apresentados os dados de temperatura da água, sendo a menor de $19,7^{\circ} \mathrm{C}$, detectada no afluente Piratininga, e a maior de $28,5^{\circ} \mathrm{C}$ no afluente Vau. Verificou-se, ainda, que as leituras amostradas no período de estiagem (maio a setembro) tiveram os menores valores em relação aos dados do período úmido (outubro a abril).

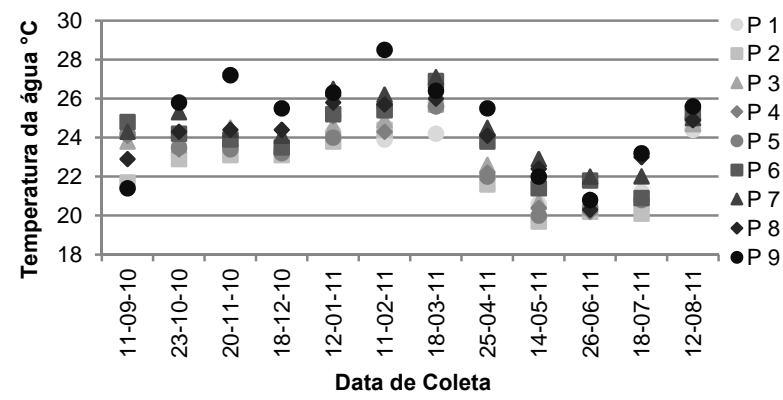

Gráfico 1 - Análise da temperatura $\left({ }^{\circ} \mathrm{C}\right)$ da água dos afluentes da UHE Barra dos Coqueiros.

As flutuações diárias de temperatura da água (Gráfico 1), em até $2,8^{\circ} \mathrm{C}$, percebidas entre os tributários da Ponte Branca e Piratininga, em relação ao Vau, pode ser explicada em função do horário do dia em que foram feitas as leituras de água. Sabe-se que, durante o dia, há uma menor incidência de radiação solar pela manhã do que no período da tarde.

Outro fator a ser levado em consideração é a proteção das margens, já que a preservação da mata ciliar proporciona o sombreamento do curso d'água, amenizando a temperatura.

Sabara (1999) encontrou valores de temperatura da água variando de 14,2 a $25,8^{\circ} \mathrm{C}$ em áreas de plantios florestais e eucalipto e, entre 17,1 a $26,6^{\circ} \mathrm{C}$ para as áreas de pastagens e agricultura, no trecho médio do rio Doce - MG. O autor conclui que o comportamento da temperatura da água é afetado pelo uso do solo, com tendência a apresentar menores valores nas áreas florestais (eucalipto) provavelmente pela condição de cobertura dos córregos, enfatizando o papel significativo da vegetação ciliar.

No Gráfico 2, observa-se que o valor menor de $\mathrm{pH}(5,7)$ foi detectado no ponto de amostragem do afluente Piratininga, e o maior valor de $\mathrm{pH}(7,5)$ foram registrados nos afluentes Guariroba e Coqueiro da margem direita. Os valores de $\mathrm{pH}$ não de- monstram estar muito afastados da neutralidade que, segundo Paula (2011), para as águas naturais do Cerrado, se caracterizam como um aspecto positivo à qualidade da água.

No entanto, as medidas de $\mathrm{pH}$ do afluente Vau estão abaixo do valor de $\mathrm{pH}$ de referência estabelecido pela Resolução CONAMA n 357/2005, para as águas destinadas ao consumo humano. Em sua localidade, existe o afloramento de rochas sedimentares da Formação Vale do Rio do Peixe, e solos pertencentes à classe de Argissolos e Neossolos, rico em quartzo, com alto teor de sílica e alumínio. Segundo Esteves (1998), estes solos, devido à solubilidade do alumínio na forma $\mathrm{Al}^{3+}$ reage com íons $\mathrm{OH}^{-}$ , aumentando a acidez da água.

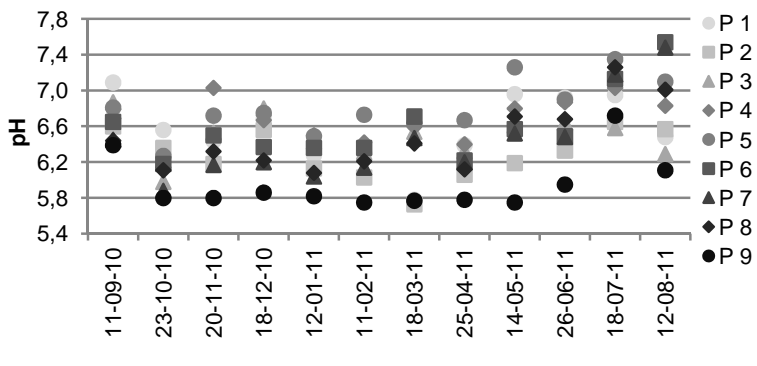

Gráfico 2 - Análise do potencial hidrogeniônico da água dos afluentes da UHE Barra dos Coqueiros.

De acordo com o Gráfico 3, o menor valor da CE foi de $10,5 \mu \mathrm{S} / \mathrm{cm}$, registrada no afluente do Vau, e o maior valor da CE de $135,8 \mu \mathrm{S} / \mathrm{cm}$ foi detectado no ponto de amostragem do afluente Coqueiro da margem esquerda, sendo alto e inadequado para as águas naturais. Apesar de a legislação em vigor não apresentar limites para a $\mathrm{CE}$, Couto $e t$ al. (2006) destacam que, nos ambientes aquáticos, a $\mathrm{CE}$ até $100 \mu \mathrm{S} / \mathrm{cm}$ são consideradas águas de boa qualidade, e acima desse valor são águas caracterizadas como impróprias ao consumo humano.

Segundo Tundisi e Tundisi-Matsumura (2008), o alto valor da CE sugere grande concentração de íons dissolvidos na água, onde, dependendo do tipo de íons e sua concentração, pode estar relacionado com a ocorrência de metais pesados, que são nocivos à saúde humana.

Em termos gerais, a CE da água apresentou valores que podem ser considerados baixos e médios, uma vez que Coluna (2007) define como baixos os valores inferiores a $50 \mu \mathrm{S} / \mathrm{cm}$, e médio entre 50 e $100 \mu \mathrm{S} / \mathrm{cm}$, sendo um indicativo de que a regi- 
ão é formada por rochas fracas e não resistentes ao intemperismo. No caso da bacia em estudo, os baixos valores de CE podem estar relacionados aos fatores litológicos, já que a mesma possui rochas basálticas da Formação Serra Geral, o que poderia resultar em água rica em carbonatos, principalmente carbonatos de cálcio $\left(\mathrm{CaCO}_{3}\right)$ ou carbonato de magnésio $\left(\mathrm{MgCO}_{3}\right)$. Já os médios e altos valores, estão associados às rochas da formação Vale do Rio Peixe e Marília, que são ricas em material carbonático, aumentando a condutividade após a dissolução.

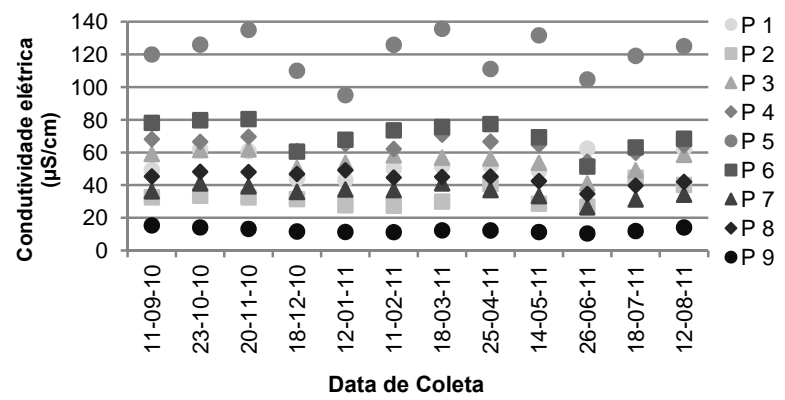

Gráfico 3 - Análise da condutividade elétrica $(\mu \mathrm{S} / \mathrm{cm})$ da água dos afluentes da UHE Barra dos Coqueiros.

Os resultados das medidas de TDS e $\mathrm{NaCl}$ são apresentados nos Gráficos 4 e 5, e estão em concordância com os resultados obtidos de CE, que se relacionam diretamente com a concentração de íons dissolvidos em solução aquosa.

Segundo a Resolução $n^{\circ}$ 357/2005 do CONAMA (BRASIL, 2005), destina-se ao consumo humano a água doce com até $250 \mathrm{mg} / \mathrm{L}$ de $\mathrm{NaCl}$ e 500 $\mathrm{mg} / \mathrm{L}$ de TDS. Mesmo considerando o limite máximo desses parâmetros, a água do ponto de amostragem do afluente do Coqueiro da margem esquerda obteve os maiores valores, mas que são inferiores ao estipulado pela resolução em vigor, demonstrando que as medidas dos afluentes estão em consonância com a Resolução CONAMA no 375/2005.

A RE é uma medida oposta à média da CE, ou seja, está ligada diretamente com a presença de íons na água. Quanto maior a concentração de Na$\mathrm{Cl}$, mais baixa a RE, e mais facilmente o material é carregado eletricamente. No Gráfico 6, o valor de $\mathrm{RE}$ menor foi de $6,8 \mathrm{~cm} . \mathrm{M} \Omega^{-1}$, no afluente Ponte Branca, e o máximo valor de $\mathrm{RE}$ foi de 107,3 $\mathrm{cm} . \mathrm{M} \Omega^{-1}$ no afluente Vau.

Conforme a Resolução CONAMA $n^{\circ}$ $357 / 2005$, a RE classificada como tipo I, deve apresentar o valor acima de $10 \mathrm{~cm} . \mathrm{M} \Omega^{-1}$ a $25^{\circ} \mathrm{C}$. Diante disso, verifica-se, no Gráfico 6, que os valores do afluente do Coqueiro esquerdo nas datas de 23/10/2010; 20/11/2010; $11 / 02 / 2011$; 18/03/2011; 25/04/2011 e 12/08/2011, estão abaixo do estabelecido pela legislação em vigor.

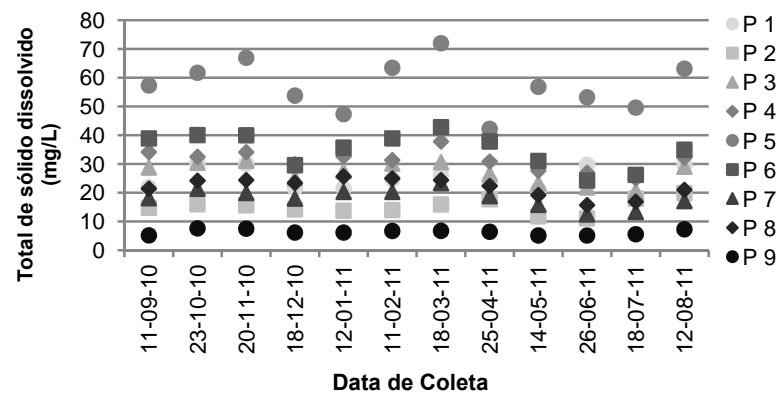

Gráfico 4 - Análise do total de sólido dissolvido (mg/L) da água dos afluentes da UHE Barra dos Coqueiros.

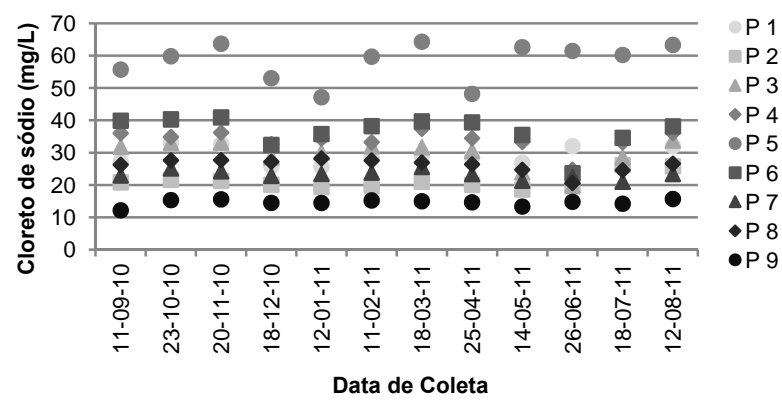

Gráfico 5 - Análise cloreto de sódio (mg/L) da água dos afluentes da UHE Barra dos Coqueiros.

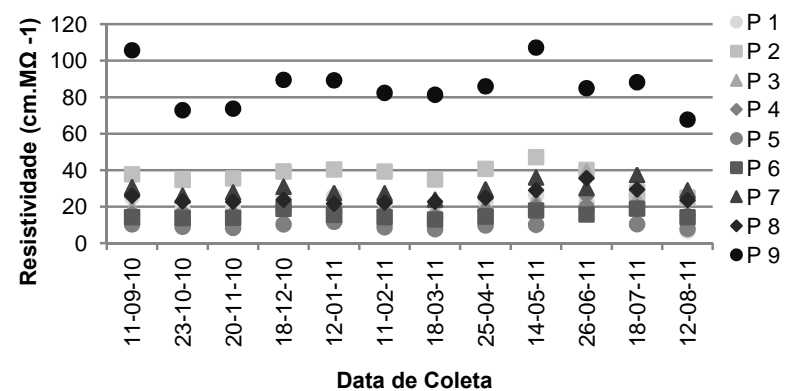

Gráfico 6 - Análise da resistividade elétrica $\left(\mathrm{cm} \cdot \mathrm{M} \Omega^{-1}\right)$ da água dos afluentes da UHE Barra dos Coqueiros.

Nota-se, no Gráfico 7, que o menor valor de turbidez encontrado foi de 0,2 NTU no afluente Vau, e o maior valor de 51,3 NTU ocorreu no afluente Coqueiro esquerdo. O pico de turbidez do Coqueiro esquerdo deve estar associado às fortes 
Tabela 1 - Correlações de Pearson entre as variáveis físicas e químicas dos afluentes da UHE Barra dos Coqueiros no Município de Caçu - Goiás. Período de estudo de setembro de 2010 a agosto de 2011.

\begin{tabular}{|c|c|c|c|c|c|c|c|c|c|c|c|c|}
\hline & 2010 & & & & 2011 & & & & & & & \\
\hline CORRELAÇÃO & 氙 & s & $\begin{array}{l}z \\
z\end{array}$ & $\begin{array}{l}\text { Na } \\
\text { D }\end{array}$ & 文 & 空 & $\sum$ & $\frac{1}{20}$ & $\sum$ & 号 & 官 & ن \\
\hline $\mathrm{T}\left({ }^{\mathrm{o}} \mathrm{C}\right) \& \mathrm{pH}$ & $-0,03$ & $-0,77$ & $-0,66$ & $-0,86$ & $-0,62$ & $-0,55$ & 0,40 & $-0,68$ & $-0,32$ & $-0,33$ & $-0,06$ & 0,15 \\
\hline $\mathrm{T}\left({ }^{\circ} \mathrm{C}\right) \& \mathrm{CE}$ & 0,64 & $-0,48$ & $-0,56$ & $-0,61$ & $-0,42$ & $-0,32$ & $-0,16$ & $-0,56$ & $-0,46$ & $-0,26$ & $-0,56$ & $-0,55$ \\
\hline $\mathrm{T}\left({ }^{\circ} \mathrm{C}\right) \& \mathrm{TDS}$ & 0,69 & $-0,45$ & $-0,54$ & $-0,59$ & $-0,38$ & $-0,29$ & $-0,10$ & $-0,51$ & $-0,42$ & $-0,26$ & $-0,54$ & $-0,53$ \\
\hline $\mathrm{T}\left({ }^{\circ} \mathrm{C}\right) \& \mathrm{NaCl}$ & 0,67 & $-0,45$ & $-0,52$ & $-0,57$ & $-0,40$ & $-0,26$ & $-0,13$ & $-0,46$ & $-0,42$ & 0,01 & $-0,53$ & $-0,54$ \\
\hline$T\left({ }^{\circ} \mathrm{C}\right) \& \mathrm{RE}$ & $-0,64$ & 0,63 & 0,83 & 0,79 & 0,40 & 0,72 & 0,19 & 0,59 & 0,32 & 0,08 & 0,71 & 0,69 \\
\hline $\mathbf{T}\left({ }^{\circ} \mathrm{C}\right) \&$ Turbidez & 0,46 & $-0,56$ & $-0,29$ & $-0,35$ & $-0,45$ & $-0,61$ & $-0,05$ & $-0,29$ & 0,33 & $-0,12$ & $-0,58$ & 0,03 \\
\hline pH \& CE & 0,47 & 0,41 & 0,74 & 0,63 & 0,86 & 0,95 & 0,66 & 0,88 & 0,82 & 0,81 & 0,44 & 0,06 \\
\hline pH \&TDS & 0,45 & 0,39 & 0,73 & 0,62 & 0,84 & 0,95 & 0,69 & 0,85 & 0,82 & 0,80 & 0,45 & 0,08 \\
\hline $\mathrm{pH} \& \mathrm{NaCl}$ & 0,47 & 0,39 & 0,71 & 0,60 & 0,84 & 0,94 & 0,66 & 0,87 & 0,79 & 0,83 & 0,43 & 0,05 \\
\hline pH \& RE & $-0,52$ & $-0,51$ & $-0,82$ & $-0,75$ & $-0,81$ & $-0,89$ & $-0,68$ & $-0,85$ & $-0,88$ & $-0,90$ & $-0,51$ & $-0,41$ \\
\hline pH \& Turbidez & 0,25 & 0,34 & 0,49 & 0,29 & 0,66 & 0,84 & 0,87 & 0,75 & 0,54 & 0,66 & 0,51 & 0,39 \\
\hline CE \& TDS & 0,99 & 0,99 & 0,99 & 0,99 & 0,99 & 0,99 & 0,99 & 0,97 & 0,99 & 0,99 & 0,99 & 0,99 \\
\hline CE \& NaCl & 0,99 & 0,99 & 0,99 & 0,99 & 0,99 & 0,99 & 0,99 & 0,98 & 0,99 & 0,93 & 0,99 & 0,99 \\
\hline CE \& RE & $-0,70$ & $-0,78$ & $-0,77$ & $-0,76$ & $-0,81$ & $-0,75$ & $-0,72$ & $-0,80$ & $-0,71$ & $-0,69$ & $-0,73$ & $-0,74$ \\
\hline TDS \& $\mathrm{NaCl}$ & 0,99 & 0,99 & 0,99 & 0,99 & 0,99 & 0,99 & 0,99 & 0,98 & 0,99 & 0,92 & 0,99 & 0,99 \\
\hline TDS \& RE & $-0,73$ & $-0,78$ & $-0,76$ & $-0,75$ & $-0,82$ & $-0,75$ & $-0,73$ & $-0,87$ & $-0,71$ & $-0,66$ & $-0,73$ & $-0,74$ \\
\hline NaCl \& RE & $-0,74$ & $-0,76$ & $-0,74$ & $-0,73$ & $-0,78$ & $-0,71$ & $-0,69$ & $-0,81$ & $-0,65$ & $-0,85$ & $-0,69$ & $-0,72$ \\
\hline CE \& Turbidez & 0,75 & 0,84 & 0,42 & 0,76 & 0,89 & 0,69 & 0,84 & 0,77 & 0,47 & 0,53 & 0,65 & 0,52 \\
\hline TDS \& Turbidez & 0,73 & 0,83 & 0,42 & 0,77 & 0,88 & 0,69 & 0,85 & 0,86 & 0,49 & 0,52 & 0,65 & 0,54 \\
\hline NaCl \& Turbidez & 0,74 & 0,82 & 0,39 & 0,76 & 0,91 & 0,67 & 0,83 & 0,85 & 0,43 & 0,66 & 0,64 & 0,51 \\
\hline RE \& Turbidez & $-0,39$ & $-0,78$ & $-0,61$ & $-0,77$ & $-0,58$ & $-0,85$ & $-0,77$ & $-0,83$ & $-0,61$ & $-0,58$ & $-0,59$ & $-0,61$ \\
\hline
\end{tabular}

Legenda: T $\left({ }^{\circ} \mathrm{C}\right)$ - Temperatura da água; pH - Potencial Hidrogeniônico; $\mathrm{CE}$ - Condutividade Elétrica; TDS - Total de sólidos dissolvido; RE - Resistividade Elétrica . Valor crítico do coeficiente de correlação de 0,666 significância para o limite de confiança de 0,05 .

chuvas e maiores quantidades de sedimentos carreados para a rede de drenagens pela enxurrada e, consequentemente, o aumento de material em suspensão no curso.

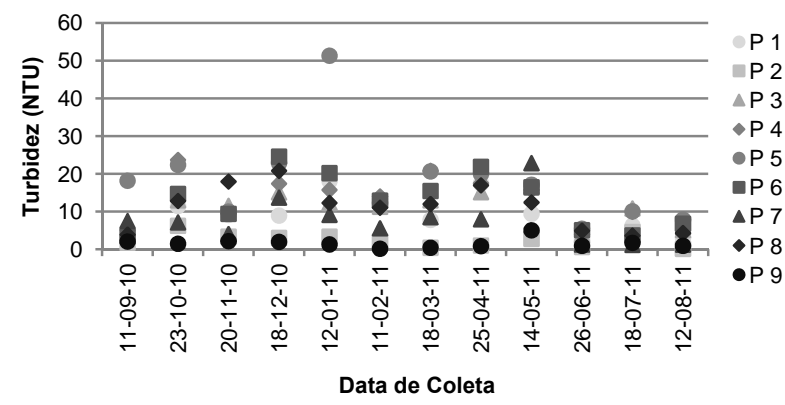

Gráfico 7 - Análise da turbidez (NTU) da água dos afluentes da UHE Barra dos Coqueiros.

\section{Análise da Correlação de Pearson}

A utilização da análise de Correlação de Pearson permitiu identificar a relação entre os parâmetros de qualidade de água e estabelecer as melhores variáveis de correlação. Na análise apresentada abaixo, foram discutidos somente os gráficos de maior coeficiente de determinação $\left(\mathrm{r}^{2}\right)$ das variáveis físico-químicas da água.

Na Tabela 1, observou-se uma correlação forte e negativa entre o $\mathrm{pH}$ e a temperatura da água nos meses de outubro a dezembro, com valores de $\mathrm{r}$ $=-0,77$ e $-0,86$, respectivamente. $O$ coeficiente de determinação $\left(\mathrm{r}^{2}\right)$ no mês de dezembro (Gráfico 8 ) indicou a melhor resposta entre as variáveis $\mathrm{pH}$ e temperatura da água. Cerca de $75 \%$ dos dados estão ajustados à linha de tendência, sendo que o afluente Pontezinha teve a medida mais dispersa da linha de tendência. Verifica-se também, que as variáveis pos- 
suem uma relação inversa, o que demonstra que, quanto menor a temperatura da água maior os valores de $\mathrm{pH}$.

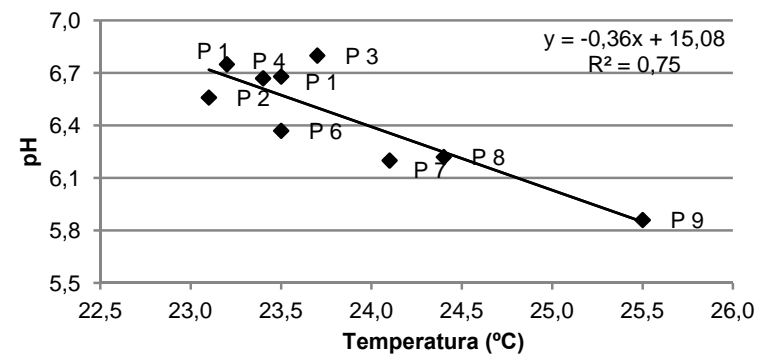

Gráfico 8 - Análise de correlação de Pearson do parâmetro $\mathrm{pH}$ e temperatura $\left({ }^{\circ} \mathrm{C}\right)$ da água do mês de dezembro de 2010.

Conforme a Tabela 1, as correlações encontradas entre os parâmetros de CE e temperatura da água, foram classificadas de fraca negativa nos meses de fevereiro ( $\mathrm{r}=-0,32)$ e março $(-0,16)$ de 2011 ; de moderada negativa nos meses de dezembro de 2010 $(\mathrm{r}=-0,61)$ e janeiro de $2011(-0,42)$; e de moderada positiva no mês de setembro de $2010(\mathrm{r}=0,64)$. As correlações fracas negativas ocorridas nos meses de fevereiro, março e junho de 2011, podem estar relacionadas à região, que é caracterizada por temperaturas muito quentes ou muito frias e com alto valor pluviométrico.

Percebe-se, no Gráfico 9, que o coeficiente que melhor se ajustou ao diagrama de dispersão foi o do mês de setembro de 2010 , com $41 \%$ dos dados ajustado linearmente. Os afluentes do Coqueiro da margem esquerda e da margem direita (P5 e P7) obtiveram as medidas mais dispersas da linha central, o que indica uma relação de afinidade média.

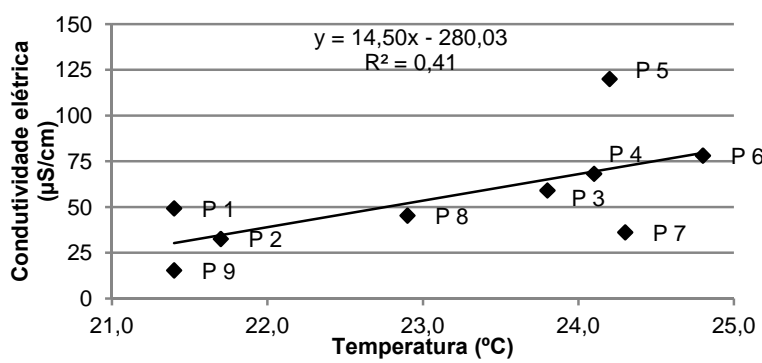

Gráfico 9 - Análise de correlação de Pearson do parâmetro condutividade elétrica $(\mu \mathrm{S} / \mathrm{cm})$ e temperatura

$\left({ }^{\circ} \mathrm{C}\right)$ da água do mês de setembro de $\mathbf{2 0 1 0}$.
As correlações entre a temperatura da água e o TDS (Tabela 1) foram classificadas de: fraca negativa, com o valor de $\mathrm{r}=-0,38$ a $-0,10$, nos meses de outubro a dezembro de 2010 e abril a agosto de 2011; moderada negativa, com os valores de $r=-0,59$ a -0,42, nos meses de janeiro a março de 2011; moderada positiva, com o valor de $\mathrm{r}=0,69$, em setembro de 2010. Já as correlações entre a temperatura da água e o $\mathrm{NaCl}$ foram classificadas como: ínfima positiva $(r=0,01)$, fraca negativa $(r=-0,26$ a $-0,13)$, moderada negativa $(r=-0,57$ a $-0,40)$ e moderada positiva $(r=0,67)$.

Verifica-se que o coeficiente linear entre a temperatura da água e o TDS obteve o maior valor, de 0,48 em setembro de 2010, demonstrando que quanto maior a temperatura da água maior é a quantidade de TDS (Gráfico 10). Entre a temperatura da água e o $\mathrm{NaCl}$ da água, o coeficiente linear foi de 0,45 no mês de setembro (Gráfico 11).

A correlação entre a variável de temperatura da água e TDS e, temperatura da água e $\mathrm{NaCl}$, apresentam valores semelhantes ao que foi obtido na correlação com a CE. Como destacado por Feitosa e Manoel Filho (2000), o aumento na concentração de íons em solução aquosa reflete diretamente no aumento desses parâmetros.

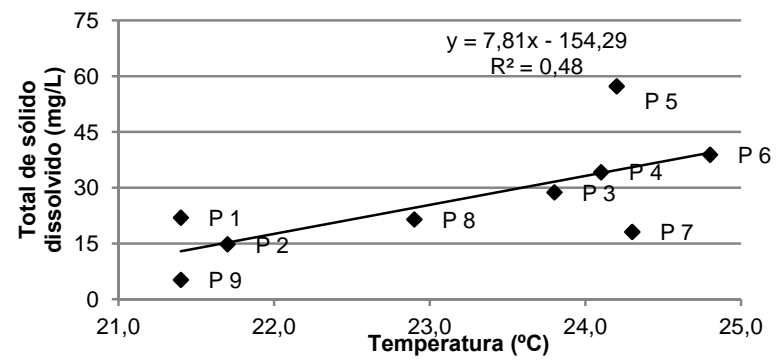

Gráfico 10 - Análise de correlação de Pearson do parâmetro total de sólido dissolvido $(\mathrm{mg} / \mathrm{L})$ e temperatura $\left({ }^{\circ} \mathrm{C}\right)$ da água do mês de setembro de 2010 .

Encontramos correlação forte positiva entre a temperatura da água e a RE nos meses de novembro/2010, dezembro/2010, fevereiro/2011 e julho/2011, com valores de $r=0,83 ; 0,80 ; 0,72 ; 0,71$, respectivamente (Tabela 1 ). No mês de junho houve correlação ínfima positiva com o valor de $r=0,08$. O maior coeficiente linear entre os parâmetros de temperatura da água e a RE da água foi no mês de novembro, com $69 \%$ dos dados ajustados à linha de dispersão. $\mathrm{O}$ afluente Piratininga teve os dados mais distantes da reta (Gráfico 12), uma vez que, em 
temperaturas baixas, teria que ocorrer uma menor RE. A sua dispersão pode ser atribuída ao horário em que foram realizadas as leituras de água, na qual se tem uma menor incidência de radiação solar sobre o corpo d'água no período matutino.

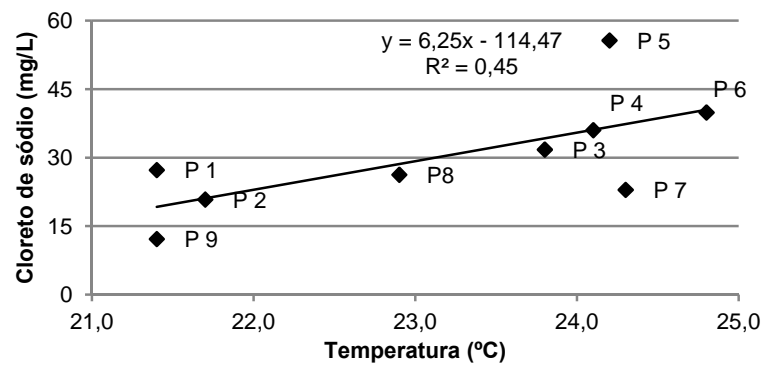

Gráfico 11 - Análise de correlação de Pearson do parâmetro Cloreto de sódio $(\mathrm{mg} / \mathrm{L})$ e temperatura $\left({ }^{\circ} \mathrm{C}\right)$ da água do mês de setembro de 2010.

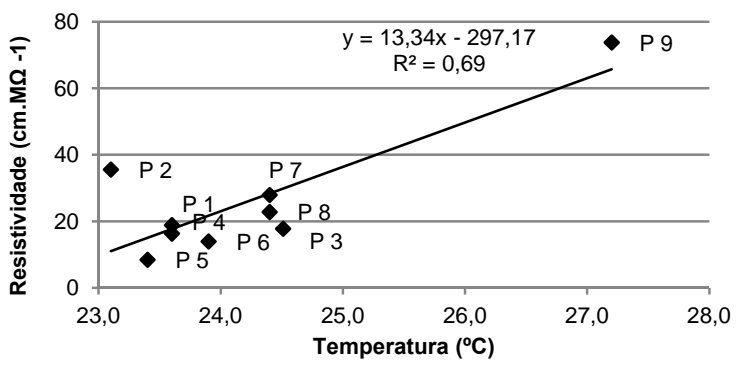

Gráfico 12 - Análise de correlação de Pearson do parâmetro resistividade elétrica $\left(\mathrm{cm} . \mathrm{M} \Omega^{-1}\right)$ temperatura $\left({ }^{\circ} \mathrm{C}\right)$ da água do mês de novembro de 2010 .

As variáveis de temperatura da água e de turbidez da água nos meses março/2011 (-0,05) e agosto de $2011(0,03)$ tiveram correlações não significativas. A correlação moderada positiva ocorreu no mês de fevereiro de 2011 (Tabela 1). Os valores dos coeficientes lineares se mostraram ajustados na ordem de 0 a $38 \%$, com uma tendência de decrescimento gradual (Gráfico 13). Os dados demonstram que não houve uma relação direta entre os parâmetros.

Observou-se entre os parâmetros de pH e a $\mathrm{CE}$, correlações ínfima positiva $(\mathrm{r}=-0,02)$ no mês agosto 2011, e moderada positiva nos meses de setembro, outubro e dezembro de 2010 , março e julho de $2011(\mathrm{r}=0,41$ a 0,66$)$. Houve também correlações forte positiva para os demais meses $(r=0,73$ a 0,95$)$. O coeficiente de determinação linear no mês de fevereiro de 2011 indicou $90 \%$ dos dados ajustados à linha do diagrama de dispersão (Tabela 1 e Gráfico $14)$.

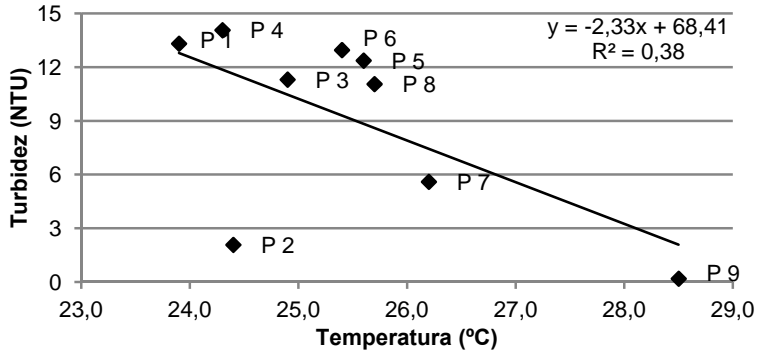

Gráfico 13 - Análise de correlação de Pearson do parâmetro turbidez (NTU) e temperatura $\left({ }^{\circ} \mathrm{C}\right)$ da água do mês de fevereiro de 2011.

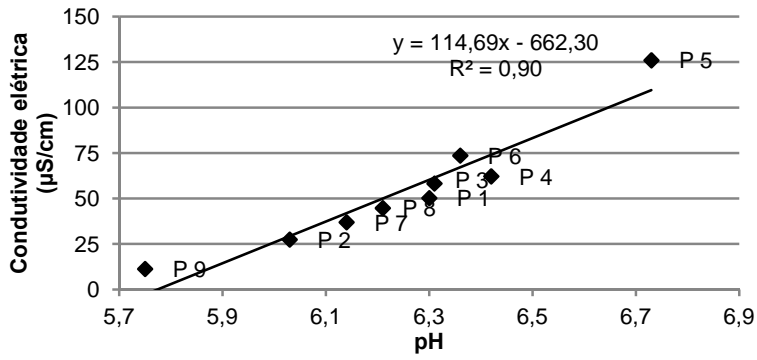

Gráfico 14 - Análise de correlação de Pearson do parâmetro condutividade elétrica $(\mu \mathrm{S} / \mathrm{cm})$ e $\mathrm{pH}$ da água do mês de fevereiro de 2011.

Verificou-se que os valores de $\mathrm{pH}$, em relação aos parâmetros de TDS e $\mathrm{NaCl}$, apresentaram respostas semelhante aos obtidos com a CE. O aumento na concentração de íons em solução aquosa reflete diretamente nos teores de $\mathrm{pH}$ e no aumento da CE. Observa-se nos Gráficos 15 e 16 que o coeficiente de determinação linear que melhor se ajustou ao gráfico de dispersão ocorreu no mês de fevereiro de 2011, ambos, com mais de $80 \%$ dos dados relacionados.

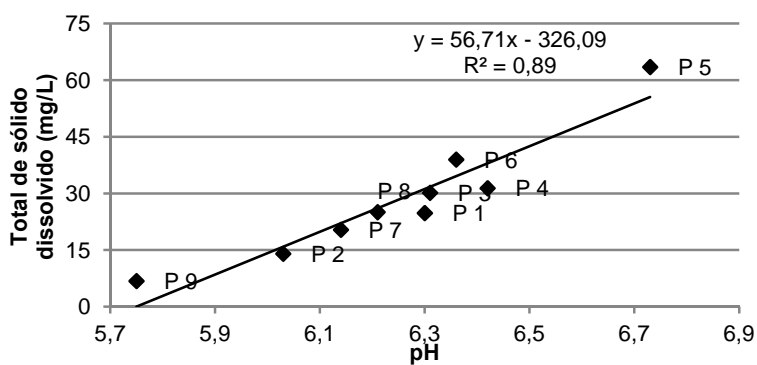

Gráfico 15 - Análise de correlação de Pearson do parâmetro total de sólido dissolvido $(\mathrm{mg} / \mathrm{L})$ e $\mathrm{pH}$ da água do mês de fevereiro de 2011. 


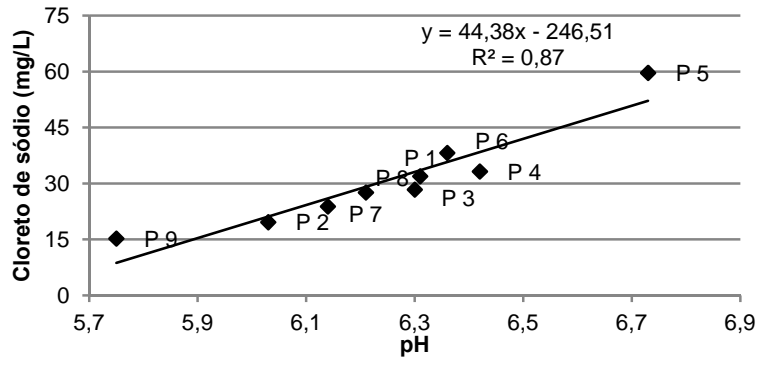

Gráfico 16 - Análise de correlação de Pearson do parâmetro cloreto de sódio $(\mathrm{mg} / \mathrm{L})$ e $\mathrm{pH}$ da água do mês de fevereiro de 2011.

As correlações obtidas entre pH e a RE foram classificadas de moderada negativa, acontecendo nos meses de setembro, outubro, março, julho e agosto com valores variando entre de $\mathrm{r}=-0,69$ a 0,41 . As correlações fortes negativas com valores variando entre $r=-0,90$ a 0,75 para os restantes dos meses (Tabela 1). O maior coeficiente de determinação linear entre os parâmetros pH e RE ocorreu no mês de fevereiro/2011, com $79 \%$ dos dados ajustados linearmente. É possível verificar que os valores mais dispersos da linha de tendência entre o pH e a RE ocorreram nos afluentes Coqueiro da margem esquerda e o Vau. Significa que, quanto menor o valor de $\mathrm{pH}$, maior é o valor de $\mathrm{RE}$ em conduzir corrente elétrica (Gráfico 17).

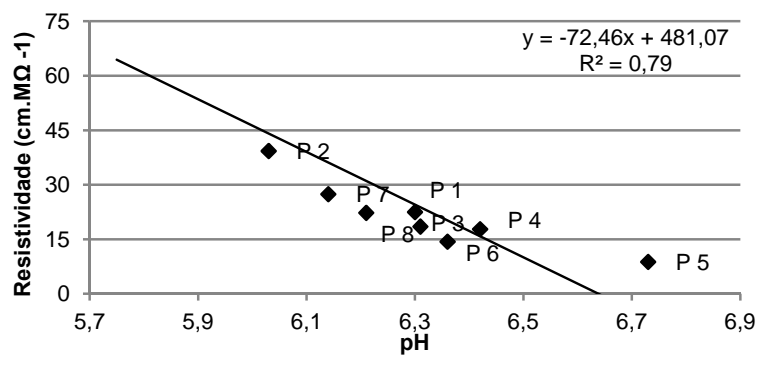

Gráfico 17 - Análise de correlação de Pearson do parâmetro resistividade elétrica $\left(\mathrm{cm} . \mathrm{M} \Omega^{-1}\right)$ e $\mathrm{pH}$ da água do mês de fevereiro de 2011.

Entre a turbidez e o pH da água, observaram-se valores de correlações de fraca, moderada e forte positivo com os valores variando de $\mathrm{r}=0,25$ (setembro) a $r=0,87$ (março). Os dados mais ajustados linearmente foram no mês de março de 2011, coincidindo com o maior volume pluviométrico da área de estudo. Os dados acompanharam $75 \%$ da linha de dispersão. Houve, assim, boas correlações entre a turbidez e o $\mathrm{pH}$, pois o aumento ou diminuição do $\mathrm{pH}$ se relaciona com a quantidade e o tipo de material presente na água (Gráfico 18).

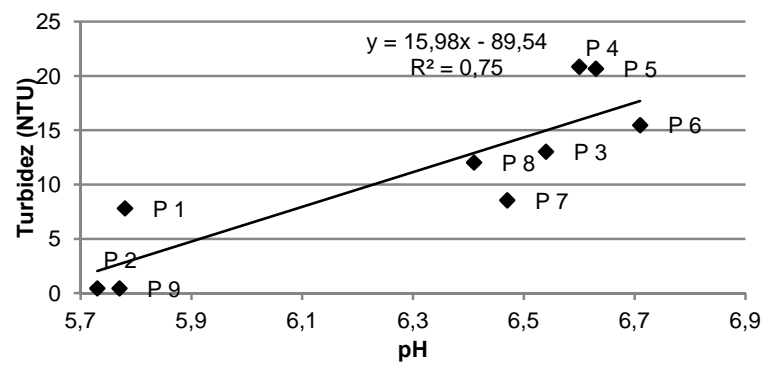

Gráfico 18 - Análise de correlação de Pearson do parâmetro turbidez (NTU) e pH da água do mês de março de 2011.

Encontramos correlações perfeitas positivas entre os parâmetros de CE e o TDS; CE e o NaCl; TDS e o NaCl (Tabela 1). O coeficiente de determinação linear $\left(r^{2}\right)$ entre a CE e o TDS indicaram resultados ajustados de 95 a 100\% (setembro/2010 a agosto/2011) (Gráfico 19). Entre a CE e NaCl, o coeficiente determinação linear $\left(\mathrm{r}^{2}\right)$ variou de 87 a $100 \%$ (setembro/2010 a agosto/2011) (Gráfico 20), já entre o TDS e o NaCl, variou de 84 a $100 \%$ (setembro/2010 a agosto/2011) (Gráfico 21). A variabilidade desses parâmetros está associada diretamente à quantidade de sal na água, sendo que a intensificação dos valores desses parâmetros é ocasionada no período seco, devido à cristalização dos minerais, aumentando a concentração de íons no meio aquático (Carneiro, 2002).

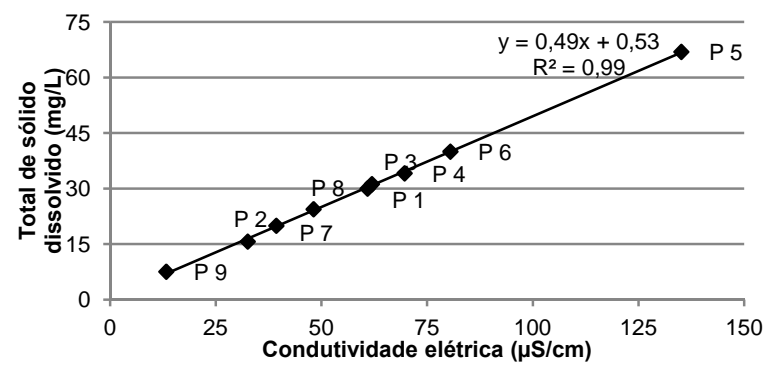

Gráfico 19 - Análise de correlação de Pearson do parâmetro total de sólido dissolvido $(\mathrm{mg} / \mathrm{L})$ e condutividade elétrica $(\mu \mathrm{S} / \mathrm{cm})$ da água do mês de novembro de 2010 . 


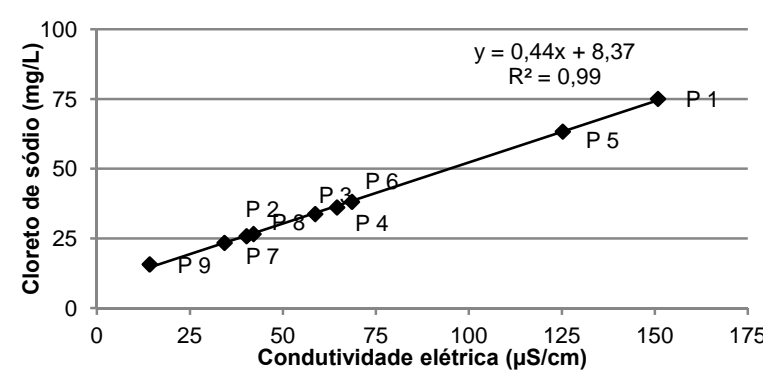

Gráfico 20 - Análise de correlação de Pearson do parâmetro cloreto de sódio $(\mathrm{mg} / \mathrm{L})$ e condutividad elétrica $(\mu \mathrm{S} / \mathrm{cm})$ da água do mês de agosto de 2011 .

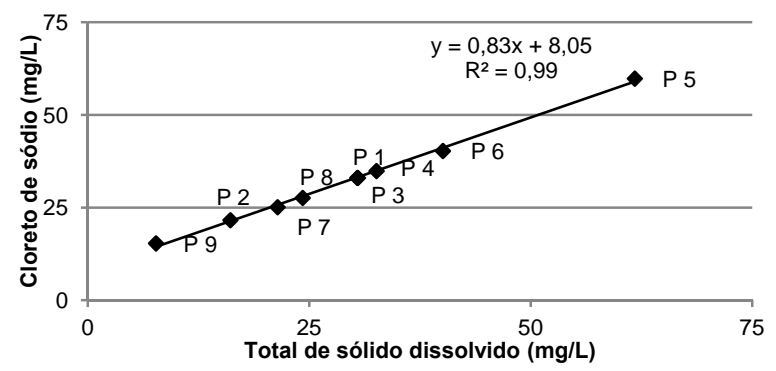

Gráfico 21 - Análise de correlação de Pearson do parâmetro cloreto de sódio $(\mathrm{mg} / \mathrm{L})$ e total de sólido dissolvido (mag/L) da água do mês de outubro de 2010.

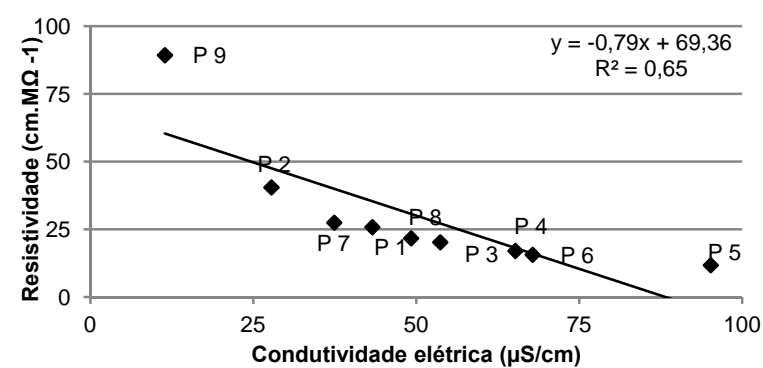

Gráfico 22 - Análise de correlação de Pearson do parâmetro resistividade elétrica $\left(\mathrm{cm} . \mathrm{M} \Omega^{-1}\right)$ e Condutividade elétrica $(\mu \mathrm{S} / \mathrm{cm})$ da água do mês de janeiro de 2011.

Ocorreram correlações moderadas negativas a fortes positivas entre a $\mathrm{CE}$ e a $\mathrm{RE}(\mathrm{r}=-0,69$ a $0,81)$, o TDS e a $\mathrm{RE}(\mathrm{r}=-0,66$ a $-0,87)$ e o $\mathrm{NaCl}$ e a $\mathrm{RE}(\mathrm{r}=-0,65$ a $-0,85)$ (Tabela 1$)$. Os coeficientes de determinação linear $\left(r^{2}\right)$ entre a CE e a RE variaram de 47 a $65 \%$, a correlação entre TDS e a RE tiveram uma variação de 44 a $75 \%$, o $\mathrm{NaCl}$ e a RE com o coeficiente variando de 43 a $72 \%$. Percebe-se, assim, que mais de $43 \%$ dos dados têm relação direta com os eixos ' $x$ ' e ' $y$ ', em relação à reta de tendência
(Gráficos 22, 23 e 24). Os valores negativos ocorrem devido à variável ' $\mathrm{x}$ ', que toma valores menores que os apresentados na variável ' $y$ ', sendo inversamente correlacionadas às variáveis.

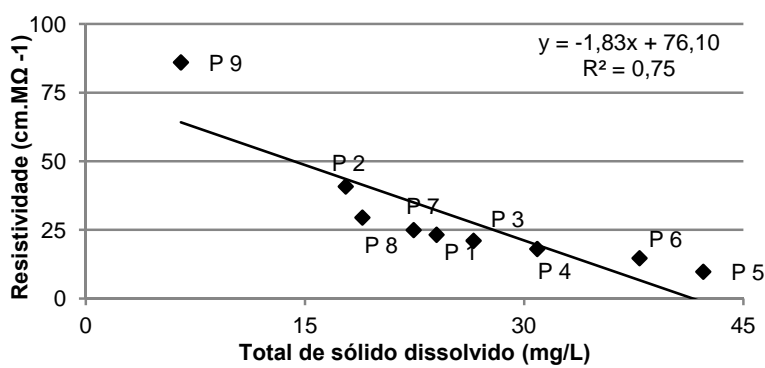

Gráfico 23 - Análise de correlação de Pearson d parâmetro resistividade elétrica $\left(\mathrm{cm} . \mathrm{M} \Omega^{-1}\right)$ e total de sólido dissolvido (mg/L) da água do mês de abril de 2011.

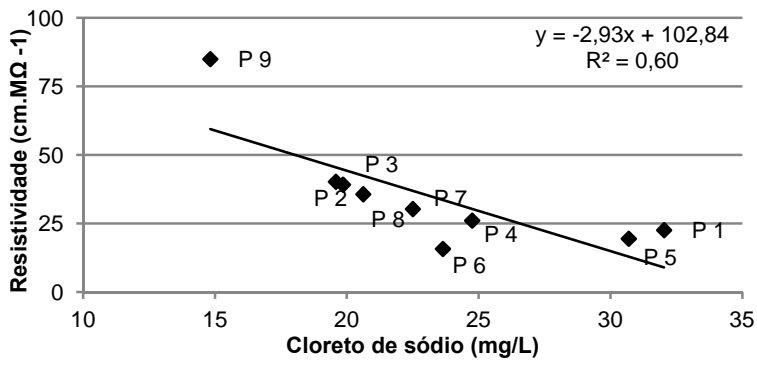

Gráfico 24 - Análise de correlação de Pearson do parâmetro resistividade elétrica $\left(\mathrm{cm} . \mathrm{M} \Omega^{-1}\right)$ e cloreto de sódio (mg/L) da água do mês de junho de 2011.

A turbidez se correlacionou moderada e fortemente com a $\mathrm{CE}$ com o menor valor de $\mathrm{r}=0,42 \mathrm{em}$ novembro/2010 e o maior valor de $\mathrm{r}=0,90 \mathrm{em}$ janeiro/2011. Houve correlações na escala de moderada a forte positiva entre a turbidez e o TDS com valores variando de $r=0,43$ a $r=0,88$, ocorrendo o menor valor no mês de novembro/2010 e o maior valor no mês de janeiro/2011. Entre a turbidez e o $\mathrm{NaCl}$, obtiveram-se as correlações classificadas de fraca positiva com o valor de $\mathrm{r}=0,40$ em novembro de 2010, e moderada positiva com valores de $\mathrm{r}=0,43$ a 0,67 , ocorrendo de maio a agosto de 2011, coincidindo com o período seco na área de estudo (Tabela 1).

Nos Gráficos 25 a 27, foram observados os coeficientes de determinação da quantidade de partículas em suspensão em relação à presença de sal na água. $\mathrm{O}$ menor coeficiente de determinação $\left(r^{2}\right)$ entre a turbidez e a CE foi de $17 \%$ no mês de 
novembro de 2010 e o maior $81 \%$ no mês de janeiro de 2011. Para os parâmetros de turbidez e o TDS, o maior coeficiente de determinação linear $\left(r^{2}\right)$ foi de $78 \%$ no mês de janeiro de 2011. Entre a turbidez e o $\mathrm{NaCl}$ no mês de novembro de 2010 , cerca de $83 \%$ dos dados ajustados à linha de dispersão.

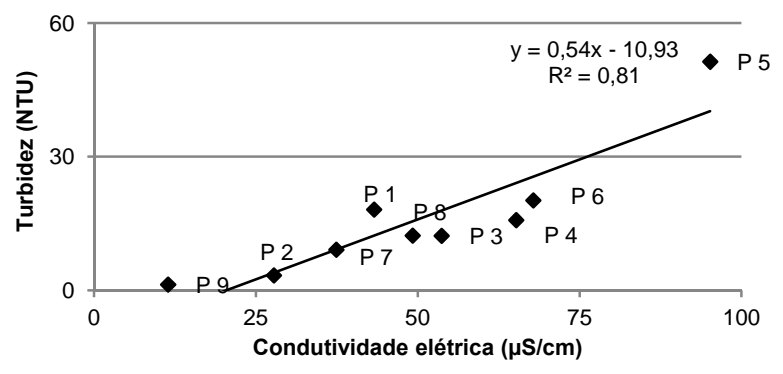

Gráfico 25 - Análise de correlação de Pearson do parâmetro turbidez (NTU) e condutividade elétrica $(\mu \mathrm{S} / \mathrm{cm})$ da água do mês de janeiro de 2011.

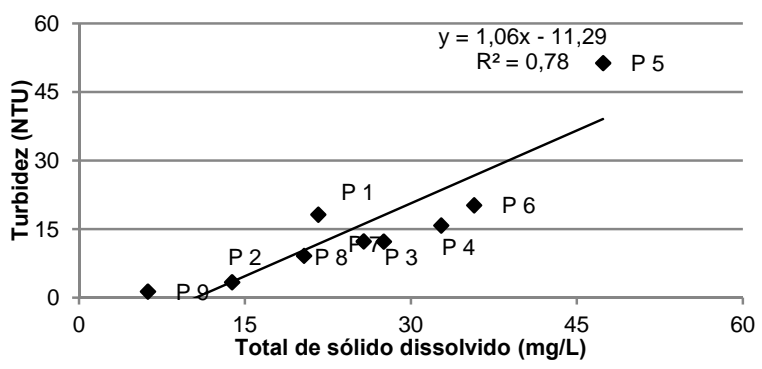

Gráfico 26 - Análise de correlação de Pearson do parâmetro turbidez (NTU) e total de sólido dissolvido $(\mathrm{mg} / \mathrm{L})$ da água do mês de janeiro de 2011.

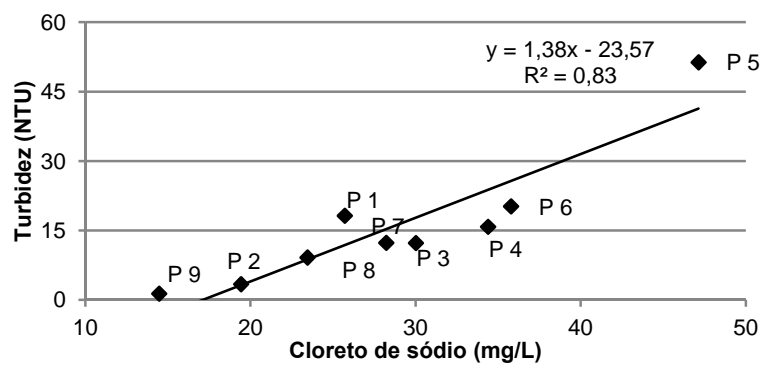

Gráfico 27 - Análise de correlação de Pearson do parâmetro turbidez (NTU) e cloreto de sódio $(\mathrm{mg} / \mathrm{L})$ da água do mês de janeiro de 2011.

As correlações obtidas entre os parâmetros de turbidez e a RE foram classificadas de fraca negativa, acontecendo no mês de setembro de 2010 ( $\mathrm{r}=-$
$0,39)$, correlações moderada negativa com os valores variando de $r=-0,63$ a 0,58 e correlações forte negativa com os valores variando de $r=-0,85$ a 0,76 . A turbidez se correlaciona com esses parâmetros por ser uma medida da quantidade de partículas suspensas na água, onde as reações químicas e biológicas são responsáveis por suas alterações (Tabela 1 e Gráfico 28).

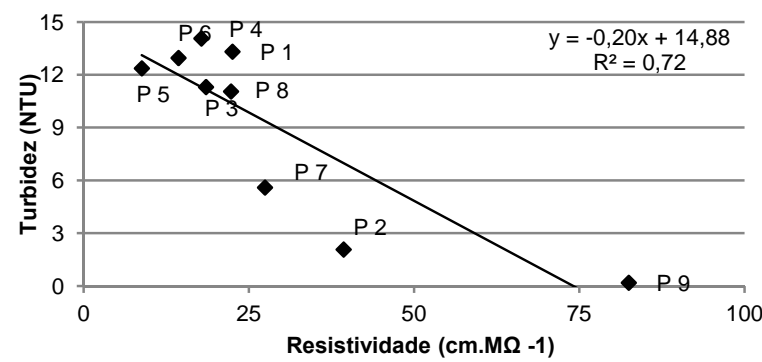

Gráfico 28 - Análise de correlação de Pearson do parâmetro turbidez (NTU) e resistividade elétrica $\left(\mathrm{cm} . \mathrm{M} \Omega^{-1}\right)$ da água do mês de fevereiro de 2011.

\section{CONCLUSÕES}

Neste trabalho, avaliaram-se alguns dos parâmetros físico-químicos de qualidade da água, de maneira espacial e temporal, e estudou-se a relação entre as variáveis utilizando a correlação de Pearson para verificação de padrões indicadores da integridade ambiental dos afluentes do reservatório da UHE Barra dos Coqueiros.

Os afluentes que apresentam inadequabilidade em relação aos parâmetros de $\mathrm{pH}$ e CE foram o Coqueiro da margem esquerda, que fornece material a partir da alteração e erosão das rochas da Formação Marília, e o Vau, que fornece material proveniente da alteração de rochas da Formação Vale do Rio do Peixe. Os parâmetros encontrados nesses dois afluentes estão fora do padrão aceito pela Resolução CONAMA n 357/2005, todavia, as demais amostras encontram-se em consonância com a legislação.

As melhores correlações das medidas limnológicas foram encontradas para os parâmetros que se relacionam diretamente com a quantidade de íons presentes na água. Os maiores valores de correlação verificados para pH e TDS; pH e NaCl, ocorreram nos meses de janeiro e fevereiro, período de maior intensidade de chuva na bacia, o que aumenta da concentração de íons nos rios. Já os maiores 
valores de correlação entre CE e TDS; CE e NaCl; TDS e $\mathrm{NaCl}$, estão relacionados à maior concentração de íons na água, possivelmente devido a precipitação na bacia; dissolução ou intemperização das rochas e solos da região e, agravadas pelas atividades antrópicas no entorno.

De acordo com análise espacial e temporal dos dados, é possível destacar que as variações estão relacionadas ao tipo do uso da terra da bacia, e aos fatores litológicos, principalmente àqueles influenciados pela Formação Vale do Rio do Peixe, que é rico em material carbonático em relação às outras formações; e a distribuição da precipitação nos 12 meses do ano.

Como perspectiva, espera-se realizar novas pesquisas no sentido de confirmar as tendências encontradas.

\section{AGRADECIMENTOS}

Os autores agradecem ao $\mathrm{CNPq}$ (processo: 472434/2009-8) pelo auxílio que viabilizou o desenvolvimento desta pesquisa.

\section{REFERÊNCIAS}

AMERICAN PUBLIC HEALTH ASSOCIATION (APHA) -AWWA; WEF. 1998. Standard Methods for the Examination of Water and Wastewater. 20. ed. Washington. 1085p.

BRASIL. Conselho Nacional do Meio Ambiente. 2005. Resolução CONAMA n 357, de 17 de março de 2005. Brasília. 27p.

CARNEIRO, F. M. 2002. Análise do estudo de impacto ambiental e da qualidade da água - o caso Açude Atalho - Brejo Santo, Ceará. Dissertação (Mestrado em desenvolvimento e meio ambiente) - Universidade Federal do Ceará/ Campus do PICI, Fortaleza-CE. $198 p$.

COUTO, T. C.; FARIA, D. C.; NAVAL, L. P. 2006. Análise das variáveis físico-químicas da água do rio javaés, ilha do bananal, entorno do Parque Nacional do Araguaia, Tocantins Brasil. In: XXX Congreso Interamericano de Ingeniería Sanitaria Y Ambiental, 2006, Punta Del Leste Uruguai. Resgatando Antiguos
Principios para los Nuevos Desafíos del Milenio; p. $1-8$.

COLUNA, N. M. E. 2007. Análise temporal e espacial da qualidade da água na bacia hidrográfica do Zerede, Timóteo - MG. In: I Seminário de Recursos Hídricos da Bacia Hidrográfica do Paraíba do Sul: o Eucalipto e o Ciclo Hidrológico, Taubaté, Brasil; p. 207-214.

ESTEVES, F. de A. 1998. Fundamentos de limnologia. $2^{a}$ ed. Rio de Janeiro: Interciência. 548p.

FEITOSA, F. A. C.; MANOEL FILHO, J. 2000. Hidrologia: conceitos e aplicações. 2. Ed. Fortaleza: CPRMREFO, LABHID-UFPE; p. 325-402.

HERMES, L. C. e SILVA, A. S. 2004. Avaliação da Qualidade das Águas. Brasília, DF: Embrapa Informação Tecnológica.

INSTITUTO BRASILEIRO DE GEOGRAFIA E ESTATÍSTICA. IBGE. 1978. Cartas topográficas na escala de 1:50.000. Rio de Janeiro.

PAULA, M.M. 2011. Análise da água e das condições ambientais da Bacia hidrográfica do Ribeirão das Pedras: Quirinópolis-GO. Dissertação (Mestrado). Universidade Federal de Goiás/ Campus Jataí, Jataí-GO. $123 p$.

ROCHA, I. R.; CABRAL, J. B. P. 2011. Uso de técnicas de sensoriamento remoto e geoprocessamento na análise da fragilidade ambiental da Bacia Hidrográfica da UHE Barra dos Coqueiros - GO. In: VIII CONPEEX - Congresso de Pesquisa, Ensino e Extensão da Universidade Federal de Goiás, Goiânia - GO.

SANTOS, C. 2007. Estatística Descritiva. Manual de Auto-aprendizagem, Lisboa, Edições Sílabo.

SABARA, M.G. 1999 Comparação ecológica entre rios de menor ordem, drenando bacias cobertas por plantios agrícolas, pastagens e plantios de Eucalyptus grandis, na região do médio Rio Doce (MG). Tese (Doutorado em Ecologia e Recursos Naturais). Universidade Federal de São Carlos, São Carlos. 259 p.

TUNDISI, J.G; TUNDISI-MATSUMURA, T. 2008. Limnologia. São Paulo: Oficina de textos. 630p. 
Spatial-Temporal Assessment of The Waters of Barra Dos Coqueiros HPP Reservoir Tributaries In Brazil

\section{ABSTRACT}

The building of hydraulic ventures interferes deeply in the physical, chemical and biological properties of water. The objective of the present article was a spatial and temporal analysis of the physical and chemical characteristics of the waters of the Barra dos Coqueiros Hydropower Plant (HPP) reservoir tributaries in the state of Goiás, in order to identify factors that interfere in the water quality. The samples of water in the tributaries were collected at approximately 30-day intervals during a one-year period. The parameters evaluated were: water temperature, hydrogen potential, total dissolved solids, conductivity, salinity, resistivity, and turbidity. The results show that the waters of some of the tributaries present inadequate physical and chemical parameters according to CONAMA Resolution $N^{\circ}$ $357 / 2005$.

Key word: Environment, water resource, Watershed 